\title{
Geociências
}

\section{Prospecção geofísica em ocorrência de cobre localizada na bacia sedimentar do Camaquã (RS)}

\author{
Geophysical prospection in a copper occurrence \\ localized in Camaquã sedimentary basin (RS)
}

\author{
César Augusto Moreira \\ Professor Assistente, Doutor \\ Universidade Estadual Paulista - UNESP \\ Campus de Rio Claro \\ cesargeologia@yahoo.com.br

\section{Lenon Melo Ilha} \\ Geofisico - Mestrando em Geociências \\ Universidade Estadual Paulista - UNESP \\ Imgeofisik@hotmail.com
}

\section{Resumo}

Estudos de pesquisa mineral são fundamentais para o reconhecimento e a incorporação de novas reservas. Esse trabalho apresenta os resultados de aplicação do método geofísico da eletrorresistividade numa ocorrência mineralizada em carbonatos de cobre, por meio da técnica de caminhamento elétrico em arranjo azimutal. A área de estudos está inserida na bacia sedimentar do Camaquã, formada por um conjunto de unidades estratigráficas sedimentares e vulcanogênicas, onde são descritas diversas ocorrências cupríferas. A presença de azurita e malaquita em fraturas e zonas de maior porosidade em arenito encaixante define a geologia local. Os modelos de inversão revelam anomalias circulares de resistividade moderada para até $25 \mathrm{~m}$ abaixo da ocorrência aflorante e anomalias de baixa resistividade em profundidades abaixo de $25 \mathrm{~m}$, além de áreas adjacentes com alta resistividade. Indicadores de mineralização descritos para ocorrências de cobre estudadas, no âmbito da bacia sedimentar do Camaquã, ocorrem na área de estudos e permitem caracterização em termos de resistividade elétrica. Áreas com silicificação apresentam alta resistividade, enquanto que valores intermediários são atribuídos a zonas com carbonatação e, finalmente, áreas de baixa resistividade, provavelmente, indicam concentrações de sulfetos disseminados.

Palavras-chave: Eletrorresistividade, arranjo azimutal, sulfeto, cobre pórfiro, minério.

\begin{abstract}
Mineral research studies are fundamental for the recognition and incorporation of new reserves. This paper presents the results of an application of the Electrical Resistivity geophysical method to a mineral occurrence of copper carbonates, by an electrical profiling technique in an azimutal array. The parameter of physical electric resistivity was measured, using the Electrical Resistivity method and the technique of electrical profiling. This study area is inserted in the Camaqua sedimentary basin, formed by sedimentary and volcanogenic stratigraphy units, where several copper occurrences are encountered. The presence of azurite and malachite in the fractures and high porosity zones in arenitic hosts define the local geology. The inversion models reveal circular anomalies of moderate resistivity up to $25 \mathrm{~m}$ below the outcropping surface, and anomalies of low resistivity for depths below 25m, besides adjacent areas with high resistivity. Mineralization indicators described for the copper occurence in the Camaqua sedimentary basin are encountered in previous studies as well as the area now studied and allow for characterization in terms of electrical resistivivity. Silicified areas present high resistivity, while intermediary values are attributed to carbonated zones, and finally, low resistivity areas probably indicate concentrations of disseminated sulfites.
\end{abstract}

Keywords: Electrical Resistivity, azimutal array, sulfide, porphyry copper, ore. 


\section{Introdução}

Estudos de prospecção e pesquisa mineral são fundamentais para o reconhecimento e a incorporação de novas reservas, em atendimento a uma demanda crescente, tanto para o mercado interno, quanto para a exportação e o equilíbrio da balança comercial. As ferramentas disponíveis compreendem métodos diretos (sondagem, amostragem de solo e rocha, análises químicas) e indiretos (analise de sensores remotos, métodos geofísicos).

Campanhas iniciais de pesquisa mineral podem compreender o uso de sensores remotos, para análise de feições morfológicas de relevo que permitem uma associação com estruturas que contenham mineralizações. Levantamentos geoquímicos são fundamentais para a detecção de zonas de concentração e sua associação com estruturas previamente determinadas. Detalhamentos em ocorrências minerais podem consistir da aplicação de métodos geofísicos terrestres, para determinação de alvos de interesse para perfuração e amostragem.

Devido ao baixo custo e à possibilidade de cobertura de amplas áreas, os métodos geofísicos constituem uma importante ferramenta em pesquisa mineral. Entre os diversos métodos passíveis de aplicação em estudos de prospecção de sulfetos e minerais metálicos, os métodos elétricos e eletromagnéticos são amplamente utilizados.

A aplicação de métodos geofísicos elétricos possibilita a caracterização de depósitos minerais a partir de anomalias em parâmetros físicos como cargabili-

\section{2. Área de estudos}

A área de estudos está localizada a noroeste da sede do município de $\mathrm{Ca}$ çapava do Sul (RS), distante cerca de $240 \mathrm{~km}$ de Porto Alegre e acessada através da rodovia BR 290. Após 1,5km do cruzamento com a rodovia BR 392, é possível acessar a vila Cerrito do Ouro, a partir da qual é possível acessar a ocorrência do Capão Grande, após $6 \mathrm{~km}$ por estrada de terra (Figura 1).

Caçapava do Sul está localizada no centro-sul do Estado do Rio Grande do Sul, com população de cerca de 32.000 habitantes e economia baseada no setor primário, na pecuária, agricultura e mineração. A região de Caçapava do Sul é, historicamente, conhecida por atividades mineiras, que remontam ao século XIX, dade e resistividade, devido ao contraste freqüentemente apresentado entre a rocha encaixante e corpos enriquecidos em minerais metálicos. O método de eletrorresistividade possui aplicação em pesquisas de cobre disseminado devido à característica de elevada condutividade elétrica desse metal, freqüentemente contrastante em relação a rochas ao redor, conforme demonstrado em diversos trabalhos de aplicação do método.

Durante levantamento no prospecto de ouro epitermal Rhyolite Creek (Austrália), Irvine \& Smith (1990) aplicam os métodos de eletrorresistividade e polarização induzida. O minério ocorre, na área de estudos, em andesitos, dacitos e sedimentos epivulcanoclasticos, com alteração hidrotermal e presença de pirita e pirofilita e gênese do tipo alta sulfetação. Foi observada uma forte anomalia de cargabilidade em conjunto com uma zona de baixa resistividade, correlacionadas à presença de veios mineralizados com $10 \%$ a $30 \%$ de pirita e de ocasionais zonas de pirita maciça de 1 metro de espessura, veios determinados a partir de sondagens e trabalhos posteriores.

Em trabalho realizado no Estado de New South Wales (Austrália), Irvine e Smith (1990) aplicam o método da eletrorresistividade numa mineralização de ouro epitermal com baixo teor de enxofre, contida em veios de quartzo em lavas basálticas para andesítica em uma seqüência vulcânica dominada por andesitos riolíticos. A zona de oxidação estende por $60 \mathrm{~m}$ abaixo da superfície, resistindo às rochas vulcânicas e a uma argila caulinítica. Os veios principais de quartzo tem uma alta resistividade em comparação com as rochas vulcânicas, enquanto que valores mais baixos de resistividade foram observados em ramificações dos veios de quartzo, ambos os valores estão relacionados a mineralizações de ouro.

Esse trabalho apresenta os resultados de um estudo geofísico realizado numa ocorrência aflorante de carbonatos de cobre em arenitos, previamente determinada por levantamentos geoquímicos em sedimentos de corrente, localizada no município de Caçapava do Sul (RS). Foi aplicado o método da eletrorresistividade por meio da técnica de caminhamento elétrico em disposição azimutal em superfície.

Essa área está inserida na bacia do Camaquã, localizada no Escudo SulRio-Grandense, sendo definida como a superposição de diferentes bacias não-individualizadas tectônica, geocronológica e termodinâmica (Paim et al., 2000; Chemale Jr., 2000) e sua evolução está relacionada com as fases finais do arrefecimento tectônico da Orogenia Brasiliana, caracterizada por diversas ocorrências de ouro e sulfetos de cobre, chumbo e zinco (Paim et al., 2000).

A potencialidade para fins de prospecção de metais básicos e a inexistência de estudos em detalhe na área selecionada, e em dezenas de ocorrências minerais conhecidas no âmbito dessa bacia, seja investigações diretas ou indiretas de subsuperfície, justificaram a realização do presente trabalho. principalmente de cobre e ouro até a década de 1990.

Nesse período, ocorreu uma queda significativa nos preços dos metais no mercado mundial, que culminou com o fechamento de diversas minas, entre elas as minas de Camaquã. Nessa minas, foram lavrados cobre por mais de 70 anos. Atualmente a atividade mineira é restrita à lavra de calcário.

A bacia sedimentar do Camaquã possui orientação NE-SW, caracterizada por grande aporte sedimentar e subsidência, com espessos pacotes sedimentares e vulcanossedimentares intercalados por intervalos marcadamente erosionais, entre o Proterozóico Superior e o Ordoviciano (Sartori \& Kawashita, 1985; So- liani Junior, 1986). A bacia é fortemente afetada por eventos deformacionais geradores de um padrão de preenchimento complexo (Kazmierczak, 2006).

A jazida de cobre mais estudada no âmbito dessa bacia é a Mina de Camaquã, que compreende a maior mina de cobre do Estado. Há, sobre essa jazida, diversos estudos relacionados à sua gênese e evolução, assim como estudos geoquímicos.

A gênese do minério dessa mina é de origem hidrotermal magmàtica, segundo Teixeira (1937), Leinz e Almeida (1941) e Costa Filho (1944), sendo tal minério encontrado como filões e preenchendo fraturas que provocam alterações na rocha encaixante, como silicificação, 


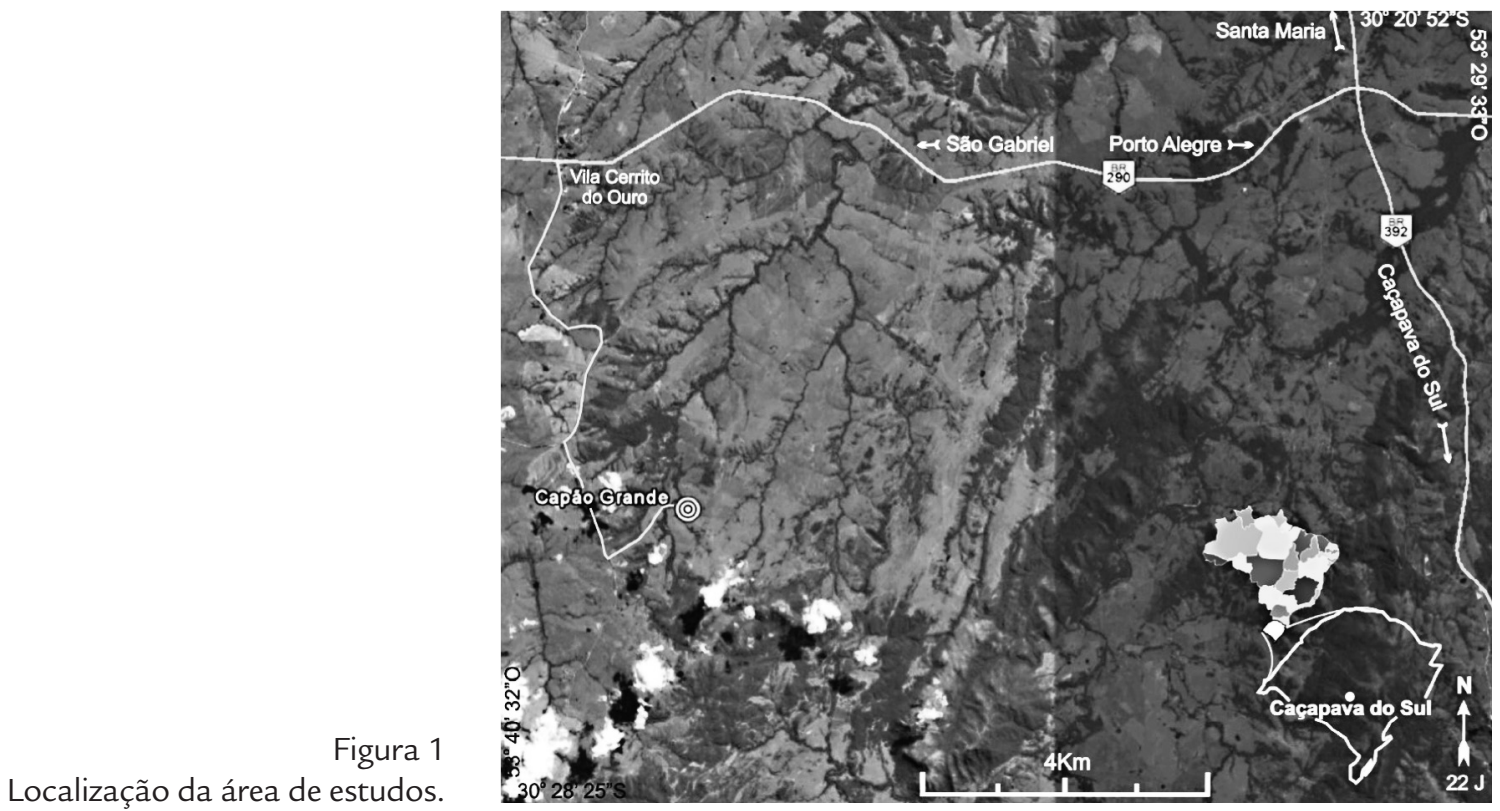

argilização e disseminações. De acordo com as hipóteses vigentes na época desses trabalhos, a ascensão de fluidos hidrotermais originados de corpos magmáticos profundos por meio de fraturas, teria ocorrido no depósito de Camaquã.

Esse modelo também é defendido no trabalho de Bettencourt (1972), com algumas variações quanto às possíveis fontes magmáticas. A partir das características apontadas nos trabalhos citados anteriormente, Beckel (1990) sugere que os fluidos hidrotermais formadores dos depósitos de Camaquã são semelhantes aos depósitos do tipo cobre pórfiro.

$\mathrm{Na}$ região de estudo, ocorrem o Complexo Metamórfico Vacacaí fácies vulcânica, a Formação Acampamento Velho, reunida no Grupo Cerro do $\mathrm{Bu}-$

Figura 2 Geologia da área de estudos.

\section{Materiais e métodos}

Foi utilizado o método da eletrorresistividade, a partir da técnica de caminhamento elétrico para as medidas de gio, e a Formação Passo da Promessa, reunida no Grupo Maricá (Figura 2).

A área de estudos consiste numa ocorrência mineral denominada Capão Grande, descrita pelo Departamento Nacional de Produção Mineral (DNPM) em 1969 (BOCCHI, 1970). Essa ocorrência mineral foi reconhecida por estudos geoquímicos em sedimentos de corrente em campanhas de pesquisa realizadas pelo DNPM na década de 60. Não existem quaisquer estudos complementares diretos ou indiretos após as referidas campanhas geoquímicas elaboradas para a área de estudos.

A ocorrência mineral essa alojada em litotipos pertencentes à Formação Passo da Promessa, caracterizada por espessos pacotes de arenitos de cores rosa-claro, cinza

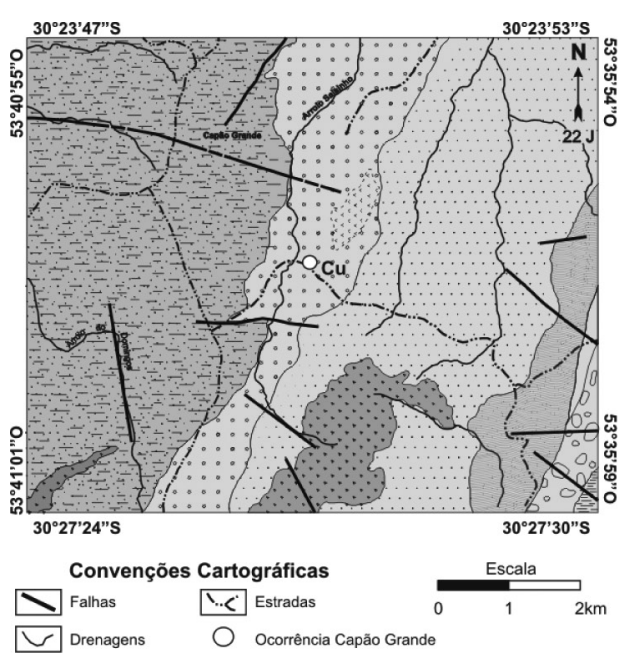

e bordô, com alternâncias de cores, dando origem a uma rocha-listrada. Apresenta, com freqüência, níveis conglomeráticos, onde os seixos são, predominantemente, de rochas graníticas e metamórficas, como granitos, gnaisses, quartzitos, xistos, anfibolitos e, ocasionalmente, seixos de rochas sedimentares silicificadas.

No local de estudos ocorre arenito arcoseano médio a grosseiro, de cor marrom-avermelhado, com possíveis fragmentos de riolito, ambos intensamente silicificados e recristalizados. A rocha apresenta a mineralizações de cobre em interstícios de fraturas e zonas de maior porosidade. A mineralização é constituída principalmente de carbonatos de cobre, especialmente malaquita e azurita, com calcosina e barita subordinada.

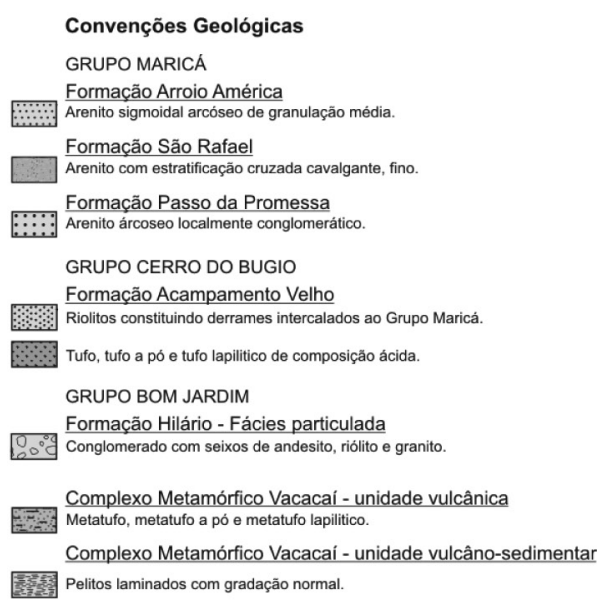

resistividade elétrica, por meio do arranjo dipolo-dipolo. Esse arranjo consiste na instalação de pares de eletrodos me- tálicos ao longo da linha de investigação, para transmissão de corrente elétrica e geração de campo elétrico em profundi- 
dade (eletrodos de corrente) e posterior leitura por meio de pares de eletrodos de recepção (eletrodos de potencial) (Orellana, 1972).

A disposição de forma adequada dos pares de eletrodos de corrente e po- tencial permite leituras de resistividade elétrica para diversos níveis de profundidade na linha investigada. Este trabalho utilizou $10 \mathrm{~m}$ de espaçamento entre eletrodos, leituras de resistividade em 20 níveis de profundidade.

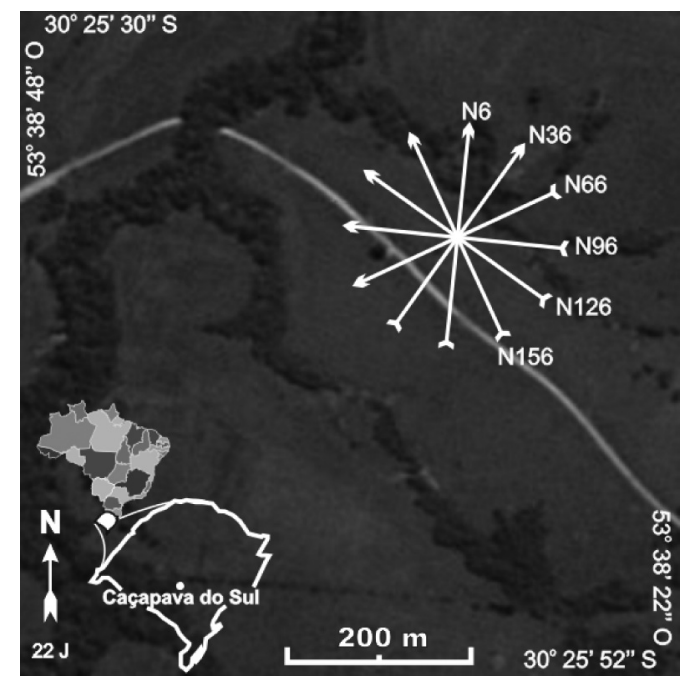

O equipamento utilizado foi o resistivímetro Syscal Pro, fabricado pela Iris (França), com resolução de $1 \mathrm{mV}$. Esse equipamento é calibrado para medidas de resistividade por meio de ciclos periódicos de corrente elétrica alternada e de baixa freqüência, procedimento que permite a filtragem de ruídos do sinal adquirido.

Os dados interpretados foram processados no software RES2DINV, apresentados sob a forma de seções distância x profundidade (Loke \& Baker, 1996) e sob a forma de modelo de inversão em termos de resistividade elétrica.

Esse programa é projetado para processamento de grandes conjuntos de dados em duas dimensões, adquiridos por meio da técnica de caminhamento elétrico. O processo de inversão consiste em uma série de blocos retangulares, a disposição dos blocos é ligada à distribuição dos pontos dos dados na pseudoseção, ou seja, seção gerada pelos dados de campo em profundidade teórica. A distribuição e tamanho dos blocos são gerados, automaticamente, pelo programa conforme a distribuição dos pontos de dados. A profundidade da linha inferior

\section{Resultados e discussão}

Em visita preliminar à área de estudos, foram realizadas medidas estruturais em fraturas e camadas, por meio de bússola. Os resultados indicaram duas famílias de fraturas, com direções N18/72NW e N112/82NE e acamamen- dos blocos é definida para ser, aproximadamente, igual à profundidade equivalente de investigação de pontos com o maior espaço entre eletrodos (Edwards, 1977).

A sub-rotina de modelagem direta é usada para calcular os valores de resistividade aparente e uma técnica de otimização não-linear por mínimos quadrados é usada para a rotina de inversão (DeGroot-Hedlin \& Constable 1990, Loke \& Barker, 1996). O resultado é apresentado sob a forma de seção com distância versus profundidade em termos de pseudo-seção, seção calculada e modelo de inversão. Nesse trabalho, são apresentados somente os modelos de inversão.

A modelagem 3D utilizou somente os dados de campo ou dados de pseudo-seção, por meio do programa Oasis Montaj desenvolvido pela Geosoft. Esse programa permite o processamento de um grande volume de dados espaciais. Permite, ainda, efetuar tarefas de processamentos complexos como: interpolação de dados, edição de mapas, edição e integração de dados de diversas naturezas.

Entre os diversos algoritmos disponíveis no programa, esse trabalho adotou to na direção N22/55NW. Com base nesse arcabouço estrutural, foi proposta a aquisição de forma azimutal.

Os resultados geofísicos, de modo geral, apresentam valores baixos a inter-

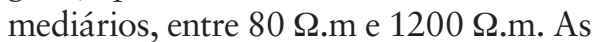

Foram realizadas seis linhas de caminhamento elétrico, com 230m de extensão cada, dispostas de forma azimutal, ou seja, radialmente com centro posicionado sobre a ocorrência mineral e ângulo entre linhas de $30^{\circ}$ (Figura 3).

Figura 3

Linhas de aquisição de dados, com centro do arranjo posicionado sobre a ocorrência mineral.

o método de mínima curvatura para interpolação dos dados de campo e geração de mapas de isovalores para todos os 10 níveis de profundidade investigados por meio do caminhamento elétrico. Posteriormente, esses mapas foram integrados sob a forma de um modelo tridimensional, cujo produto é apresentado nesse trabalho.

A interpolação consiste em um procedimento matemático de ajuste de uma função em pontos não amostrados, baseada em valores obtidos em pontos amostrados. A partir dos pontos amostrados, é definido um reticulado com espaçamento relativo aos pontos. $\mathrm{O}$ valor de cada nó do reticulado é calculado por seleção de pontos mais próximos conhecidos, que, posteriormente, são filtrados de modo a suavizar os contornos resultantes e a permitir o melhor ajuste com os valores originais.

Entre os vários métodos disponíveis, esse trabalho utiliza o método de mínima curvatura, segundo o qual equações diferenciais ajustam uma superfície. São efetuados cálculos de derivação repetidamente até que seja alcançada uma convergência entre os valores amostrados e os estimados. linhas $\mathrm{N} 156^{\circ}, \mathrm{N} 126^{\circ}$ e $\mathrm{N} 36^{\circ}$ são caracterizadas pela presença de uma anomalia circular de baixa resistividade, em torno de $80 \Omega . m$, localizada no centro das seções, posição de exposição em superfície da ocorrência mineral (Figura 4). 


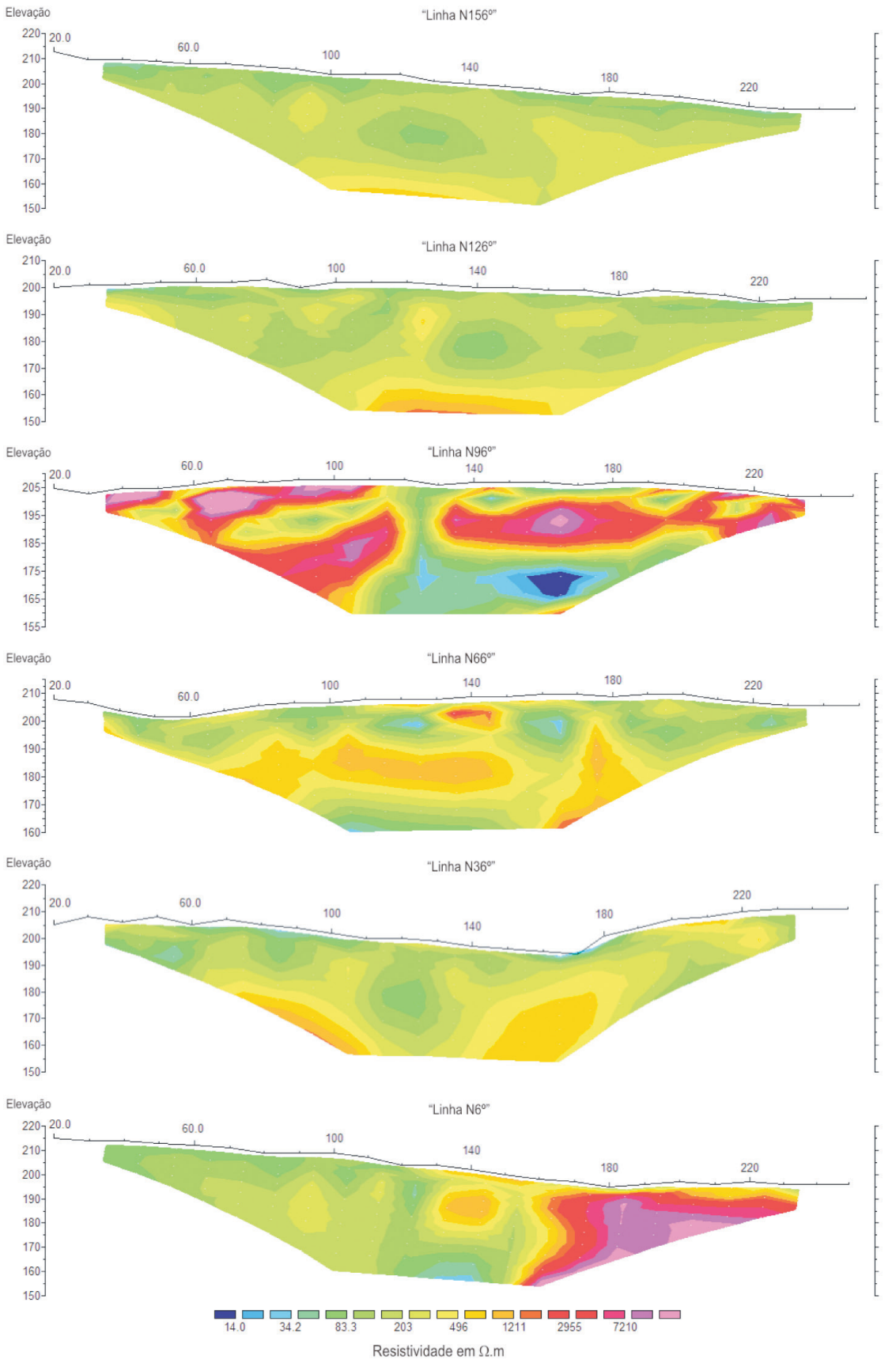

A linha $\mathrm{N} 66^{\circ}$ apresenta uma anomalia com valores intermediários de cerca de $1500 \Omega . m$, localizada próximo à superfície entre duas anomalias de baixa resistividade de aproximadamen-

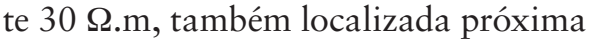
à superfície, ambas as anomalias descritas estão sobre uma faixa horizontal de valores intermediários.

$\mathrm{Na}$ linha $\mathrm{N}^{\circ}$, é encontrada uma anomalia circular de resistividade intermediária de, aproximadamente, 1200 $\Omega . m$, localizada próxima ao centro da seção. Essa seção apresenta, ainda, uma zona com valores muito elevados, até 8000 S.m, localizada entre as posições $120 \mathrm{~m}$ a $160 \mathrm{~m}$, desde a superfície até a base da seção.

A linha $\mathrm{N} 96^{\circ}$ apresenta os maio-

res contrastes de valores de resistividade entre as demais, caracterizada por uma anomalia horizontal com valores altos , localizada entre $100 \mathrm{~m}$ a $180 \mathrm{~m}$ sobre outra anomalia horizontal, que apresenta valores baixos entre $15 \Omega . m$ e 70 S.m. A zona entre $0 \mathrm{~m}$ e $80 \mathrm{~m}$ apresenta valores intermediários a muito altos, variando de $100 \Omega . m$ a $8000 \Omega . m$.

A integração das linhas em modelo 3D permite uma visualização adequada das zonas de baixa resistividade em superfície e em profundidade, com destaque para a maior intensidade dessa área em profundidade, quando comparada com o intervalo de superfície (Figura 5).

Os baixos valores de resistividade descritos nas seções $\mathrm{N} 156^{\circ}, \mathrm{N} 126^{\circ}$ e N36, provavelmente, representam a direção principal de mineralização. As direções $\mathrm{N} 18^{\circ}$ e $\mathrm{N} 112^{\circ}$ correspondem às principais famílias de fraturamento, ambas preenchidas por carbonatos e hidróxidos de cobre, além de barita e quartzo, descritos na área.

Estudos realizados na Mina do Camaquã por Bettencourt (1972) revelam que a mineralização está condicionada por zonas de fraturamento, com movimentos recorrentes e mudanças na composição das soluções mineralizadoras. Inicialmente as soluções seriam ricas em sílica, ferro e enxofre, com enriquecimento posterior em cobre, numa fase de fraturamento posterior, e responsáveis pela deposição de sulfetos. Novas ativações tectônicas teriam provocado a reabertu- 


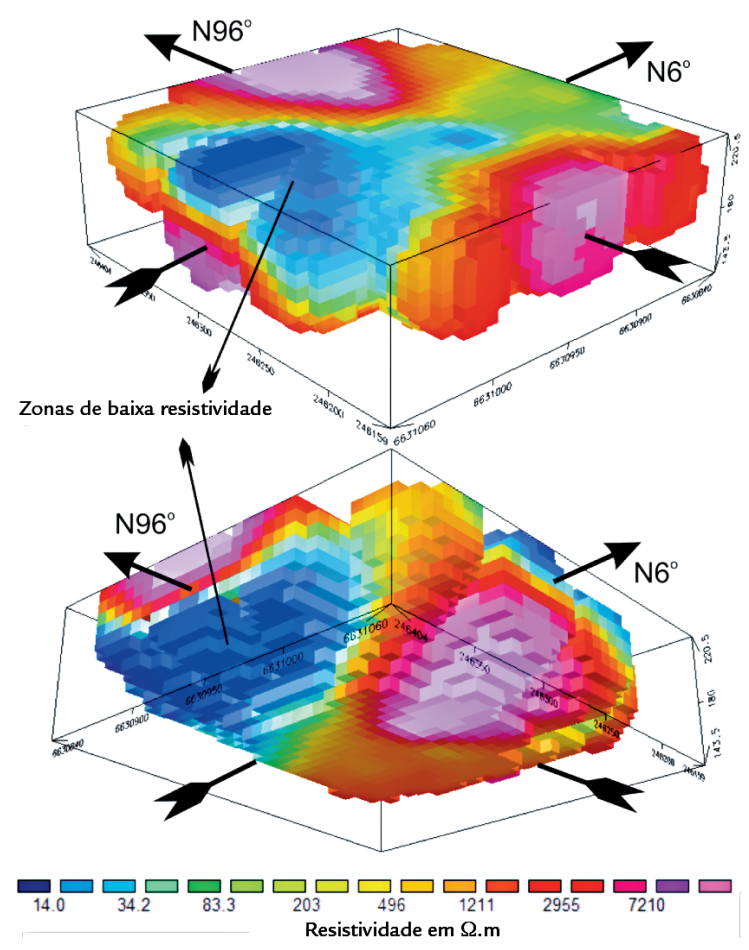

ra de fraturas mineralizadas e quase no final deste ciclo de deposição, a concentração de ferro e magnésio foi suficiente para a cristalização de hematita especular e clorita, além de quartzo subordinado. O ciclo de mineralização é encerrado com a deposição de pirita e calcopirita em baixas concentrações, acompanhada pela decomposição de quartzo, calcita e barita.

Aliado a essa proposta, Beckel (1990) descreve que as mineralizações cupríferas clássicas encontradas em toda bacia do Camaquã revelam uma distribuição regional marcadamente linear, associadas a falhamentos com direção geral $\mathrm{N} 20^{\circ} \mathrm{E}$.

A linha $\mathrm{N}^{\circ}$ apresenta uma zona anômala na região central, com resistividade intermediária, que pode ser correlacionada a uma zona com presença de hidróxidos e carbonatos de cobre,

\section{Conclusões}

O método da eletrorresistividade demonstrou resultados satisfatórios na caracterização da ocorrência cuprífera, pois permite relacionar os resultados de modelamento com a ocorrência mineral aflorante e sua provável continuidade em profundidade, devido ao contraste nas propriedades físicas entre as rochas encaixantes e a zona mineralizada. Grande parte dos modelos de inversão de resistividade apresenta anomalias circulares de baixa intensidade, possivelmente relacionadas à mineralização devido ao compor- presentes no afloramento em superfície. Abaixo dessa zona anômala, são observados valores mais baixos de resistividade, que podem estar associados à presença de carbonatos de cobre.

A linha N96 apresenta uma zona anômala em profundidade em termos de resistividade elétrica, que pode ser correlacionada à presença de sulfetos devido à baixa resistividade, em semelhança a seção N6․ Essa zona está localizada sob a área de afloramento superficial dos carbonatos e hidróxidos e apresenta continuidade lateral.

Essa linha cruza de forma ortogonal uma das famílias de fraturas medidas na ocorrência aflorante em campo, ou seja, N18/72NW. Esta coincide com a direção descrita para diversas ocorrências cupríferas no âmbito da bacia do Camaquã e, provavelmente, representa o caminho preferencial de acesso de líquidos hi- tamento condutivo dos sulfetos.

O modelo provavelmente associado à gênese da ocorrência mineral estudada é o de cobre pórfiro, o qual apresenta alterações associadas à carbonatação e silicificação. As áreas de resistividade descritas nas adjacências da área central podem corresponder a zonas de silicificação. Por outro lado, a zona central de baixa resistividade pode indicar uma área de carbonatação, fato evidenciado pela presença de malaquita e azurita em superfície.

Os dados obtidos, nesse estudo, não
Figura 5

Modelo 3D de resistividade.

drotermais à área da ocorrência mineral.

Os locais que apresentam elevados valores de resistividade elétrica podem ser relacionados a zonas de silicificação. $\mathrm{O}$ cimento silicático que preenche os poros do arenito apresenta comportamento de um condutor dielétrico, ou seja, dificuldade ao trânsito de corrente elétrica.

A descrição em campo de barita em fraturas associada à presença de carbonatos de cobre pode indicar que a área estudada representa a fase final de mineralização regional ou que a ocorrência aflorante em superfície represente apenas uma área adjacente a depósitos de sulfetos, visto que, em superfície, ocorre calcosina de forma subordinada em conjunto com

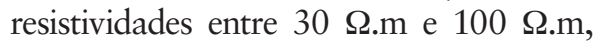
enquanto que em profundidade ocorrem valores entre $4 \Omega . m$ e $30 \Omega . m$, nesse caso, tais resistividades estão associadas à presença de sulfetos em maiores quantidades. permitiram o estabelecimento da profundidade máxima de ocorrência mineral, pois, aparentemente, há continuidade abaixo de $50 \mathrm{~m}$. Contudo a presença de anomalias de resistividade entre $5 \Omega . \mathrm{m}$ e $30 \Omega . \mathrm{m}$ presentes abaixo de $25 \mathrm{~m}$ de profundidade pode indicar a presença de zonas com preenchimento de cimento carbonático.

Os indícios de anomalias pronunciadas em direções preferenciais podem ser indicativos de percolação de fluidos hidrotermais em fraturas. A seção N96 ${ }^{\circ}$ apresenta uma anomalia vertical de bai- 
xa resistividade, entre $120 \mathrm{~m}$ e $130 \mathrm{~m}$, que pode indicar uma zona fraturada.

Os resultados apresentados, nesse trabalho, são baseados em dados indiretos, em descrições geológicas locais e em estudos quanto a gênese do minério realizados em outras partes da bacia do $\mathrm{Ca}$ -

\section{Agradecimentos}

Os autores agradecem ao proprietário da fazenda Dona Rosa pelo acesso à área de estudos, além das geofísicas $\mathrm{Ca}$ -

\section{Referências bibliográficas}

maquã. Contudo a correlação entre padrões de resistividade elétrica com feições comuns em mineralizações do tipo cobre pórfiro como silicificação e carbonatação permite recomendar estudos geoquímicos de superfície, posteriormente complementados por análises diretas por meio de perfuração e amostragem de rocha e geoquímica para avaliação de teores.

A presença de feições genéticas semelhantes em áreas bastante estudadas como as das Minas do Camaquã também corrobora para se efetuarem estudos diretos e de maior detalhe para a área. mila Schweig e Monica Teixeira de Oliveira pelo auxilio nas atividades de campo. Agradecemos, ainda, a Universidade
Federal do Pampa - Campus de Caçapava do Sul (RS) pelo auxilio no transporte e liberação do equipamento.

BECKEL, J. Metalogenía del Cu, Pb y Zn em la Cuenca de Camaquã durante el ciclo orogênico Brasiliano, RS (Brasil). Espanha: Universidade de Salamanca, 1990. 275 p. (Tese de Doutorado).

BETTENCOURT, J. S. A mina de cobre de Camaquã, Rio Grande do Sul. São Paulo: Instituto Astronômico e Geofísico, Universidade de São Paulo, 1972. 175 p. (Tese de Doutorado).

BOCCHI, P. R. Geologia da Folha de Caçapava do Sul, Rio Grande do Sul. Rio de Janeiro, DNPM, Boletim 245. 1970. 86p.

CHEMALE Jr. F. Evolução geológica do Escudo Sul-Riograndense. In: HOLZ, M., DE ROS, L. F. (Org.). Geologia do Rio Grande do Sul. Porto Alegre: Universidade Federal do Rio Grande do Sul, 2000. p.13- 52.

COSTA FILHO, J. H. Prospecção das minas de cobre de Camaquã, Rio Grande do Sul. DNPM. Ministério da Agricultura. Boletim n ${ }^{\circ}$ 59, p. 13-94, 1944.

DEGROOT-HEDLIN, C. \& CONSTABLE, S. Occam's inversion to generate smooth, two-dimensional models form magnetotelluric data. Geophysics, 55, p. 16131624, 1990.

EDWARDS, L.S. A modified pseudosection for resistivity and induced polarization. Geophysics, 42, p.1020-1036, 1977.

IRVINE, R. J., SMITH, M. J. Geophysical exploration for epithermal gold deposits. Journal of Geochemical Exploration, v. 36, p 375-412, 1990.

KAZMIERCZAK, T. S. Mapeamento da bacia do Camaquã com a utilização de dados geofísicos, geologia e sensoriamento remoto. Porto Alegre: Instituto de Geociências, Universidade Federal do Rio Grande do Sul, 2006. 110 p. (Dissertação de Mestrado).

LOKE M. H., BARKER R. D. Rapid least-squares inversion of apparent resistivity pseudosections by quasi-Newton method. Geophysical Prospecting, 44, p. 131$152,1996$.

LEINZ, V., ALMEIDA, S. C. Gênese da jazida de cobre "Camaquam”, município de Caçapava - Rio Grande do Sul. Secretaria dos Negócios de Agricultura Indústria e Comércio do Estado do Rio Grande do Sul, DPM, Boletim nº 88, 1941, 56 p.

ORELLANA, E. Prospeccion geoeletrica en corriente continua. Biblioteca Técnica Philips. Madrid: Paraninfo, 1972. 523 p.

PAIM, P., CHEMALE Jr, F., LOPES, R. C. A Bacia do Camaquã. In: HOLZ, M., DE ROS, L. F. (Org.). Geologia do Rio Grande do Sul. Porto Alegre: Universidade Federal do Rio Grande do Sul, 2000. p. 231-274.

SARTORI, P. L., KAWASHITA, K. Petrologia e geocronologia do Batólito Granítico da Caçapava do Sul, RS. In: SIMPÓSIO SUL-BRASILEIRO DE GEOLOGIA, 2. Florianópolis, Anais..., SBG, p. 102-115, 1985.

SOLIANI JUNIOR, E. Os dados geocronológicos do Escudo Sul-rio-grandense e suas implicações de ordem geotectônica. São Paulo: Instituto de Geociências, Universidade de São Paulo, 1986. 425p. (Tese de Doutorado).

TEIXEIRA, E. Cobre no Rio Grande do Sul. Boletim da Divisão de Fomento da Produção Mineral, DNPM. Rio de Janeiro. Avulso 22.1937.29p. 